\title{
Effect of Shading on Biomass and N Mass Partitioning in Paddy Rice Seedlings through Allometric Analysis
}

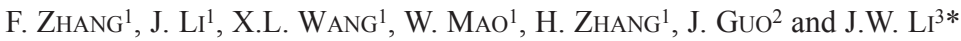 \\ ${ }^{1}$ Xinjiang Vocation \& Technology College of Communications, Urumuqi, China \\ ${ }^{2}$ Xinjiang Academy of Forestry, Urumuqi 830000, China \\ ${ }^{3}$ Shanghai Academy of Environmental Sciences, Shanghai, China
}

(Received 2 August 2016; Accepted 26 September 2016;

Communicated by R.K. Behl)

\begin{abstract}
An allometric analysis of biomass and $\mathrm{N}$ mass allocation of rice (Oryza sativa L.) seedlings under non-shaded (100\% of full sunlight) and shaded (30\% of full sunlight) treatments were conducted. The allometric slopes and the intercepts were estimated using standardized major axis regression. Results indicated that biomass was preferentially allocated to stems during plant ontogeny, and leaves and roots were isometric when rice seedlings were not shaded. Under shade, however, more biomass was allocated to leaves and stems. $\mathrm{N}$ mass allocation was also altered by shading in that more $\mathrm{N}$ mass was allocated to the aerial shoots, and plants accumulated less $\mathrm{N}$ mass when shaded. Our study revealed that both biomass and $\mathrm{N}$ mass were in accordance with the optimal partitioning theory.
\end{abstract}

Keywords: optimal partitioning theory, ontogeny, paddy rice, standardized major axis regression

\section{Introduction}

How plants respond to variations in environmental resources such as light, nutrients, water, etc., is a central question in modern plant ecology. According to the optimal partitioning theory, plants shift more photosynthate to the leaves and stem when photosynthetically active radiation (PAR) is more limited than nutrients, and to the roots when PAR was less limited than nutrients (McConnaughay and Coleman 1999; Bloom and Mooney 2003; Aikio et al. 2009). However, biomass partitioning may change in a predictable way as a function of plant size (total biomass) during plant development, which was attributed to ontogenetic drift (Evans 1972). Regardless of the effect of different resource levels, the root:shoot ratio of plants gradually decreased with plant development (Gedroc et al. 1996; Geng et al. 2007).

To separate ontogenetic and plastic characteristics, allometry, which is defined as the quantitative relationship between plant size and phenotypic traits, is a powerful tool for accounting for plant development over time and was thus useful for the research on biomass allocation (Poorter et al. 2012). The allometric relationship can be described by a power law of the form:

*Corresponding author; E-mail: lijw@saes.sh.cn 


$$
y=\beta x^{\alpha},
$$

where $x$ and $y$ are the masses of different organs, and $\alpha$ and $\beta$ are the scaling exponent and the allometric constant, respectively. West et al. (1997) proposed a metabolic scaling theory based on optimization of the fractal-like design of the vascular transport system, and predicted constant scaling exponents (such as $3 / 4$ for metabolic rate versus size) across large ranges of plant size. However, Poorter et al. (2015) rejected the theory, finding instead that scaling exponents and biomass fractions shifted dynamically with plant size. The leaf-versus-stem and leaf-versus-root scaling exponents, for example, decreased from about 1.00 for small plants to 0.60 for the largest trees.

Nitrogen $(\mathrm{N})$ is vital to photosynthesis, and $\mathrm{N}$ concentrations in plant tissues vary considerably as a function of the availability of resources, including light and nutrients. Generally, the $\mathrm{N}$ concentration of crops decreased with the growth of plant (Sadras and Lemaire 2014). Nevertheless, to our knowledge, the allometry of $\mathrm{N}$ mass versus plant size and the allocation of $\mathrm{N}$ between different organs have rarely been studied. Bernacchi et al. (2007) found that $\mathrm{N}$ uptake for plants harvested at the same time was affected by external resources (such as light, nutrient, and $\mathrm{CO}_{2}$ ), but the allometry of whole-plant $\mathrm{N}$ versus non-N biomass accumulation remained the same over a wide range of external resources gradients.

The objectives of this paper were to study the allometry of rice seedlings between different organs, and to determine how shading treatment resulted in changes in biomass and $\mathrm{N}$ mass between the organs. We tried to determine whether adjustments in biomass partitioning in rice seedlings under shaded treatment - beyond adjustments resulting from ontogenetic drift - was related to the optimal partitioning theory. Through comparing the allometric relationships between $\mathrm{N}$ uptake amount and non- $\mathrm{N}$ biomass, we wanted to find whether $\mathrm{N}$ accumulation was changed by shading when compared to seedlings of the same size.

\section{Materials and Methods}

\section{Experiment design}

A potted experiment was conducted in a greenhouse from May to July 2013, and the rice cultivator Xiushui 63 was selected as the subject. According to previous measurements, the root length of Xiushui 63 was less than $0.4 \mathrm{~m}$. Therefore, to allow for the unlimited growth of rice roots, plastic pots with a depth of $0.5 \mathrm{~m}$ and a diameter of $0.4 \mathrm{~m}$ were chosen and filled with sieved soil. The soil organic matter and total $\mathrm{N}$ contents were $40.50 \mathrm{~g}$ $\mathrm{kg}^{-1}$ and $4.2 \mathrm{~g} \mathrm{~kg}^{-1}$, respectively. Rice seeds were sown into the pots on May 5, and 5 homogeneous seedlings were retained in each pot before shading treatment began. Half of the pots (randomly selected) were covered by black nylon mesh. The PAR of the pots was measured by external quantum sensor of a gas analyzer (Li-6400; Licor, USA). The PAR of the shaded pots was approximately $30-40 \%$ of the non-shaded pots. There were a total of 36 replicates for the shaded and non-shaded treatments, respectively. 


\section{Measurements}

Rice plants were sampled at 10-day intervals beginning 20 days after sowing (DAS). The precise measurement of root biomass was a difficult task. In order to completely gather entire plant roots, the pots were cleaved and the roots with soil were taken out. Any soil adhering to the roots, especially to the lateral roots, was carefully washed away by water. Plants were divided into root, stem and leaf. Because the plant was in vegetative stage, there was no spike apparent. Each part was overdried to a constant weight $\left(70^{\circ} \mathrm{C}\right)$. After weighing, samples were frozen using liquid $\mathrm{N}$ and ground into a fine power. The $\mathrm{C}$ and $\mathrm{N}$ contents were determined using an elemental analyzer (Vario EL III, Germany) with double replicates. The $\mathrm{N}$ mass was calculated by multiplying biomass and $\mathrm{N}$ concentration for each part. Non-N biomass of the seedling was equal to total biomass minus $\mathrm{N}$ mass.

\section{Statistics}

After logarithmic transformation, the allometric relationships were described by the following equation:

$$
\ln (y)=\beta+\alpha \ln (x),
$$

where $x$ was the root biomass, root $\mathrm{N}$ mass or total $\mathrm{N}$ mass, and $y$ was the stem or leaf biomass or the shoot $\mathrm{N}$ mass, and $\mathrm{ln}$ was natural logarithm. The scaling exponent and allometric constant were estimated using standardized major axis regression (SMA; SMATR Version 2.0; Warton et al. 2006) on ln-transformed data. The numerical values of $\alpha$ were compared to determine if they were consistent with an isometric relationship, i.e. $\alpha=1.0$, which was taken as the null hypothesis.

\section{Results}

\section{Biomass allocation between different organs}

Biomass partitioning between leaves and roots was almost isometric in the rice grown without shading, and the scaling exponent (0.99) was not significantly different from 1 $(P=0.552$, Table 1$)$. When the seedlings were shaded, the allocation patterns were allometric (scaling exponent $=1.07$, significantly different from $1, P=0.002$ ). In the shaded treatment, the allometric regressions were above those in the non-shaded treatment (Fig. 1a). Scaling exponents of the two regressions were significantly different from each other (test statistic $=7.932, P=0.006$ ). Thus, for a given root biomass, the rice seedlings allocated more biomass to leaves when the rice seedlings were shaded (Fig. 1a).

The scaling exponent of the allometry of stem biomass versus root biomass or leaf biomass under shaded or non-shaded treatments were all significantly higher than 1 $(P<0.001)$, as this value was outside the $95 \%$ confidence interval (CI, Table 1$)$. The scaling exponent of the allometry of stem biomass versus root biomass were not changed by shading (test statistic $=0.169, P=0.687$, Table 1 ), but the allometric constants of the two regressions were significantly different from each other $(P<0.001)$. In the shaded treat- 

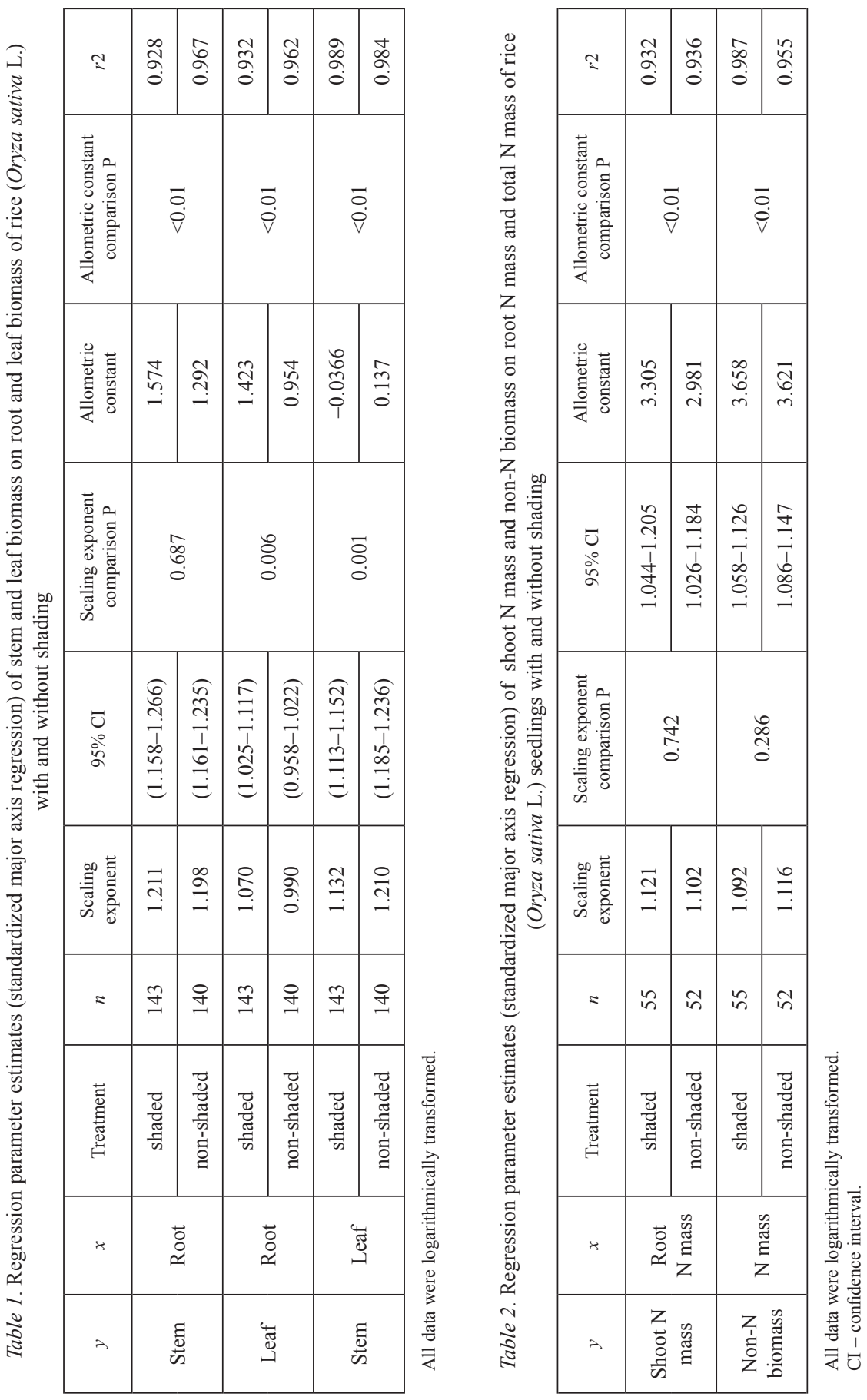

Cereal Research Communications 45, 2017 

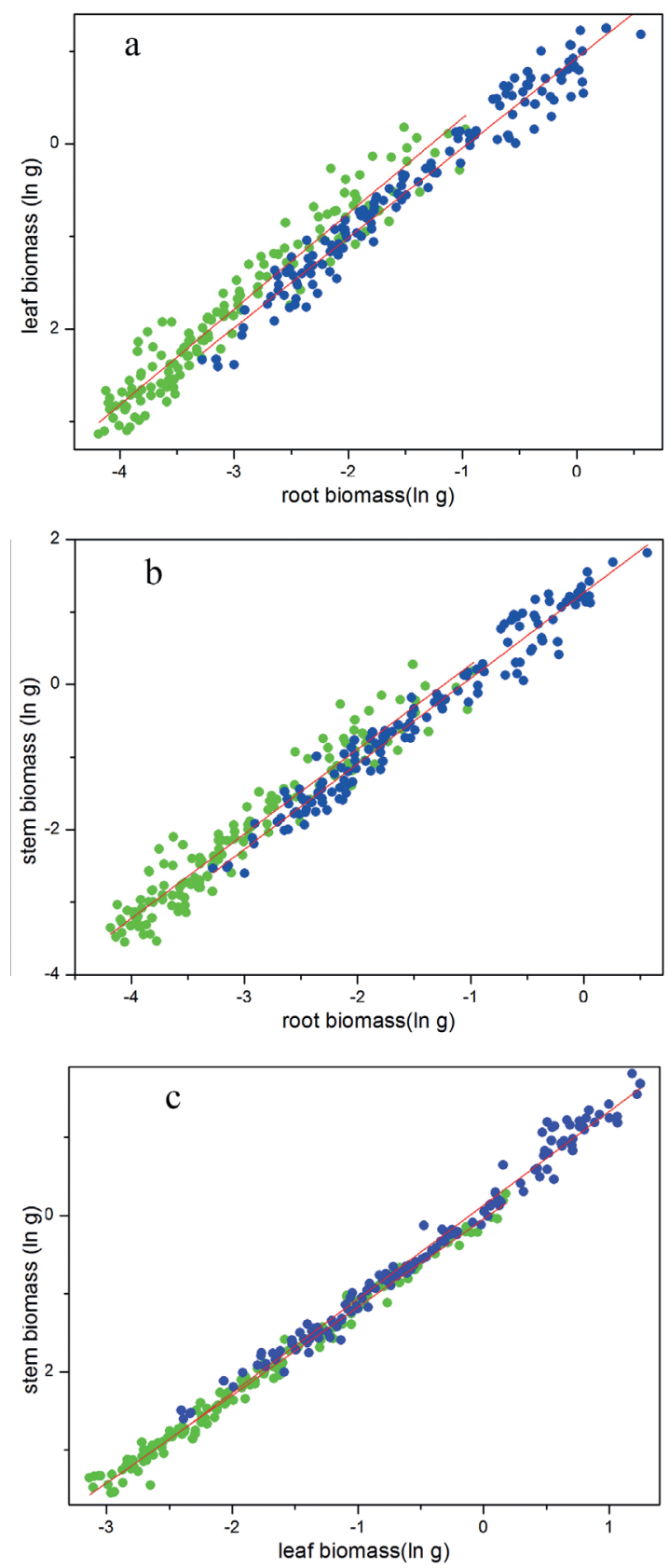

Figure 1. Leaf biomass - root biomass relationship (a), stem biomass - root biomass relationship (b) and stem biomass - leaf biomass relationship (c) of rice (Oryza sativa L.) seedlings under shaded (green) and nonshaded treatments (blue). All data were logarithmically transformed. Parameters fitted by the standardized major axis are given in Table 1 
ment, the allometric regressions were above those of the non-shaded treatment (Fig. 1b). For the same root size, more biomass was allocated to stems when the plant seedlings were shaded (Fig. 1b). Shading significantly lowered the scaling exponent of the allometric relationship between stem biomass and leaf biomass (test statistic $=22.731, P=0.001$ ). More biomass was allocated to leaves when plant seedlings were shaded (Fig. 1c).

\section{$N$ allocation between root and shoot and $N$ accumulation}

The allocation of $\mathrm{N}$ between roots and shoots (including leaves and stems) was also allometric. The scaling exponents of allometry of shoot $\mathrm{N}$ mass versus leaf $\mathrm{N}$ mass under shaded and non-shaded treatments were 1.121 and 1.198 , respectively, and both were significantly higher than $1(P=0.002,0.009$, respectively, Table 2$)$. Shading did not alter the scaling exponents of the two regressions (test statistic $=0.116, P=0.742$ ). In the shaded treatment, the regression was above that of the non-shaded treatment (Fig. 2a), with allometric constants of the two regressions significantly different from each other $(P<0.001)$. Comparing the same root $\mathrm{N}$ mass, rice seedlings allocated more $\mathrm{N}$ to shoots when shaded.

$\mathrm{N}$ and non- $\mathrm{N}$ biomass accumulations in rice seedlings under shaded or non-shaded conditions were indicated in Fig. 2b. For the same non-N biomass, the accumulation of $\mathrm{N}$ was lower when the rice seedlings were shaded (Fig. 2b). The scaling exponents of the allometry for non- $\mathrm{N}$ biomass versus $\mathrm{N}$ mass in rice seedlings under shaded and nonshaded treatments were 1.092 and 1.116, respectively, which were not statistically different from each other (test statistic $=1.073, P=0.286$, Table 2 ), but statistically different from $1(P<0.001)$. The regression line of the shaded treatment was above that of the non-shaded treatment (Fig. 2b), with allometric constants of the two regressions significantly different from each other $(P<0.001)$.
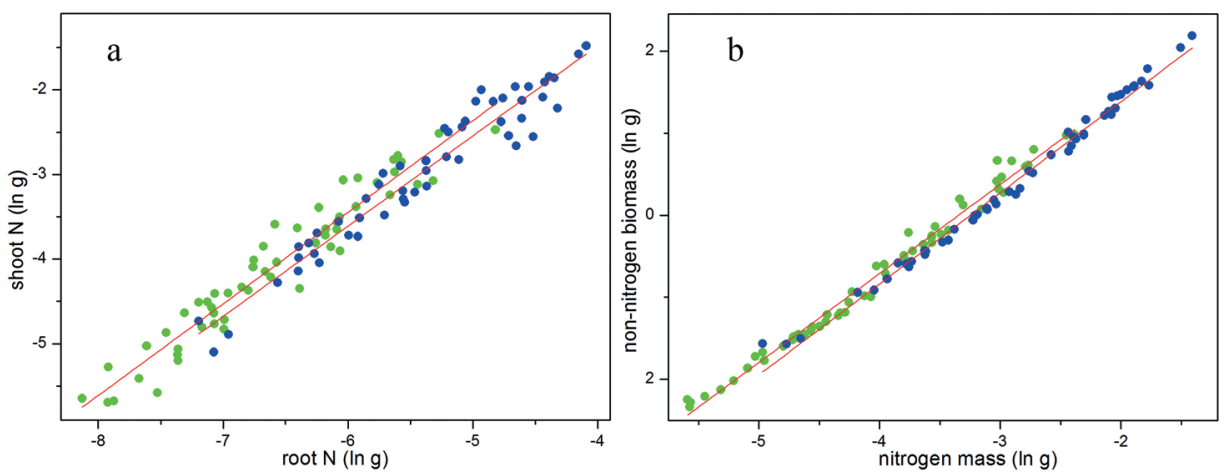

Figure 2. Shoot N mass - root N mass relationship (a), and non-nitrogen biomass - N mass relationship (b) of rice (Oryza sativa L.) seedlings under shaded (green) and non-shaded treatments (blue). All data were logarithmically transformed. Parameters fitted by the standardized major axis are given in Table 2 


\section{Discussion}

Rice seedlings could be classified into the species of "small plant" (the total biomass was less than $10 \mathrm{~g}$ in this study), as described by Poorter et al. (2015). The present study demonstrated that the rice seedling, as a small plant, had higher scaling exponents than $3 / 4$, which was consistent with the findings of Poorter et al. (2015), who stated that small plants show scaling coefficients of around 1.0. Allometric analysis indicated that biomass was initially allocated to the stem along the whole ontogenetic trajectory of rice seedlings in the vegetative stage (the scaling exponent of the allometry of stem versus leaves or roots was significant at greater than $1 ; P<0.001)$. Stems were the organ in which panicle primordium developed. The rice seedlings probably allocated more biomass to the stem for reproduction. In other words, the stem acted as a carbohydrate sink. Therefore, the authors assumed that the allometry of stems versus leaves or roots could be attributed to the sink effect.

Semchenko and Zobel (2005) found that rice plants displayed ontogenetic plasticity in leaf area, leaf mass, specific leaf mass (the ratio of leaf mass to area), stem mass and root mass. At the same time, the effect of shading, fertilization and breeding altered the scaling exponent or allometric constant as well. Shading significantly changed the allometric constant of stem biomass versus root biomass. The main hypothesis was probably related to the role played by the stems in the mechanical support of leaves for carbon (C) fixation (Normand et al. 2008), and because the stems contained chlorophyll, they could also assimilate small amounts of C. Therefore, it was believed that when shaded, a greater proportion of carbohydrates were allocated to stems, not only to allow the leaves to capture more $\mathrm{C}$, but also for fixing $\mathrm{C}$. The variations in the scaling exponents of allometric regression of stems versus leaves indicated much more biomass was allocated to leaves when the plants were shaded. Therefore, the present study was in accordance with the optimal allocation theory, which was supported by the variation of scaling exponents or allometric constant of the allometry of leaves versus root and stems. Nevertheless, the physiological mechanism of $\mathrm{C}$ allocation affected by shading was unclear. Use of an isotope tracer $\left(\mathrm{C}^{13}\right)$ found no preferential allocation of recent $\mathrm{C}$ to aboveground organs when plants were shaded (Bahn et al. 2013), so in-depth study of this point should be conducted.

Besides biomass allocation, the allocation of $\mathrm{N}$ between roots and the aerial shoots were also affected by shading. More $\mathrm{N}$ mass was allocated to shoots when plants were shaded, and the $\mathrm{N}$ mass was closely related to chlorophyll, which assimilated $\mathrm{C}$ in the leaves. Allometric analysis indicated that to cope with shading, both biomass and $\mathrm{N}$ mass were allocated to aerial shoots to capture more $\mathrm{C}$. The scaling exponents of allometry of non-N biomass versus $\mathrm{N}$ mass were statistically different from 1 (1.092 and 1.116 for shaded and non-shaded treatments, respectively), indicating the $\mathrm{N}$ concentration was diluted by biomass. It is worth noting that the shading significantly altered the $\mathrm{N}$ mass versus biomass allometry. Therefore, for a given plant size, the rice accumulated less $\mathrm{N}$ when the light was limited. Lemaire and Salette (1984) proposed the concept of the critical $\mathrm{N}$ concentration in aerial biomass, which, in vegetative stage, corresponded to the 
minimum concentration of $\mathrm{N}$ necessary to achieve maximum aboveground biomass. This concentration was represented by a power equation ( $\mathrm{N}$ dilution curve):

$$
C N=a M^{-b}
$$

where $M$ is the dry mass of shoots per unit ground area, $C N$ is the $\mathrm{N}$ concentration in the shoot on a dry mass basis, and $a$ and $b$ are constants. Obviously, the coefficients of the N dilution curve of rice plants grown in climatic zones with different average light intensity should be different.

Biomass allocation of rice seedlings under different PAR treatments can have both plastic and ontogenetic components. The biomass was initially allocated to the stem during plant ontogeny, but shading significantly altered both biomass and $\mathrm{N}$ allocation, as determined through allometric analysis. Rice plant seedlings accumulated less $\mathrm{N}$ mass when shaded compared to plants of the same size. Our results indicated that both biomass and $\mathrm{N}$ allocation were consistent with the optimal partitioning theory.

\section{Acknowledgements}

The study was financed by the Natural Science Fund of Shanghai (No. 2014ZR1435000), Innovation Fund of Shanghai Academy of Environmental Sciences (No. CX201406), and Natural Science Fund of Xinjiang (No. 2016D01B016). We are thankful to the anonymous referees for the helpful comments.

\section{References}

Aikio, S., Rämö, K., Manninen, S. 2009. Dynamics of biomass partitioning in two competing meadow plant species. Plant Ecol. 205:129-137.

Bahn, M., Lattanzi, F.A., Hasibeder, R., Wild, B., Koranda, M., Danese, V., Brüggemann, N., Schmitt, M., Siegwolf, R., Richter, A. 2013. Responses of belowground carbon allocation dynamics to extended shading in mountain grassland. New Phytol. 198:116-126.

Bernacchi, C.J., Thompson, J.N., Coleman, J.S., Mcconnaughay, K.D.M. 2007. Allometric analysis reveals relatively little variation in nitrogen versus biomass accrual in four plant species exposed to varying light, nutrients, water and $\mathrm{CO}_{2}$. Plant Cell Environ. 30:1216-1222.

Bloom, A.J., Mooney, H.A. 2003. Resource limitation in plants - an economic analogy. Ann. Rev. Ecol. Syst. 16:363-392.

Evans, G.C. 1972. The Quantitative Analysis of Plant Growth. University of California Press, California, USA.

Gedroc, J.J., McConnaughay, K.D.M., Coleman, J.S. 1996. Plasticity in root/shoot: optimal, ontogenetic, or both? Func. Ecol. 10:44-50.

Geng, Y.P., Pan, X.Y., Xu, C.Y., Zhang, W.J., Li, B., Chen, J.K. 2007. Plasticity and ontogenetic drift of biomass allocation in response to above- and below-ground resource availabilities in perennial herbs: a case study of Alternanthera philoxeroides L. Ecol. Res. 22:255-260.

Lemaire, G., Salette, J. 1984. Relation entre dynamique de croissance et dynamique de prelevement d'azote pour un peuplement de graminees fourrageres. I. Etude de l'effet du milieu (Relationship between growth and nitrogen uptake in a pure grass stand. I. Environmental effects). Agronomie 4:423-430. (in French)

McConnaughay, K.D.M., Coleman, J.S. 1999. Biomass allocation in plants: ontogeny or optimality? A test along three resource gradients. Ecology 80:2581-2593. 
Normand, F., Bissery, C., Damour, G., Lauri, P.-E. 2008. Hydraulic and mechanical stem properties affect leaf-stem allometry in mango cultivars. New Phytol. 178:590-602.

Poorter, H., Niklas, K.J., Reich, P.B., Oleksyn, J., Poot, P., Mommer, L. 2012. Biomass allocation to leaves, stems, and roots: meta-analyses of interspecific variation and environment control. New Phytol. 193:30-50.

Poorter, H., Jagodzinski, A.M., Ruiz-Peinado, R., Kuyah, S., Luo, Y., Oleksyn, J., Usoltsev, V.A., Buckley, T.N., Reich, P.B., Sack, L. 2015. How does biomass distribution change with size and differ among species? An analysis for 1200 plant species from five continents. New Phytol. 208:736-749.

Sadras, V.O., Lemaire, G. 2014. Quantifying crop nitrogen status for comparisons of agronomic practices and genotypes. Field Crop. Res. 164:54-64.

Semchenko, M., Zobel, K. 2005. The effect of breeding on allometry and phenotypic plasticity in four varieties of oat (Avena sativa L.). Field Crop. Res. 93:151-168.

Warton, D.I., Wright, I.J., Falster, D.S., Westoby, M. 2006. Bivariate line fitting methods for allometry. Biol. Rev. 81:259-291.

West, G.B., Brown, J.H., Enquist, B.J. 1997. A general model for the origin of allometric scaling laws in biology. Science 276:122-126. 